\title{
At either end of the tube
}

This patient, who was a junior doctor when he was faced with open heart surgery, recounts his experience of postoperative intensive care, with help from his friend Robin Kerr to distinguish between hallucination and reality

\section{Barry M Schyma specialist trainee year 3, anaesthesia and critical care ${ }^{1}$, Robin Kerr GP specialist trainee year $3^{2}$, Shirjel Alam cardiology research fellow ${ }^{3}$}

${ }^{1}$ Royal Infirmary of Edinburgh, Edinburgh EH16 4SA, UK; ${ }^{2}$ Eastfield Medical Practice, Penicuik EH26 8EZ, UK (robinkerr@nhs.net); ${ }^{3}$ University of Edinburgh, Medical School, Edinburgh EH8 9AG (shirjel@doctors.org.uk)

This is one of a series of occasional articles by patients about their experiences that offer lessons to doctors. The BMJ welcomes contributions to the series. Please contact Peter Lapsley (plapsley@bmj.com) for guidance.

We are often told that experiencing illness will make us better doctors. Perhaps one of the more extreme examples of this is being intubated and sedated in the intensive care unit five weeks before starting work there.

I was in the second month of my foundation year 1 . I had been sent home on two consecutive days for vomiting on the ward, and when I returned colleagues mentioned that I had lost weight. As I struggled to clerk a patient for an elective finger operation, he commented, "I think that you are more unwell than I am, doctor." The rigors continued through that day, and I was sent home again in blissful ignorance of the severity of my condition. I continued to feel dreadful, became anuric, and was admitted to our hospital's medical assessment unit. A medical student took my history, performed an examination with an incredibly detailed neurological component, and presented a diagnosis of viral gastroenteritis. I was beginning to become concerned, but the medical team reassured me that my high $\mathrm{C}$ reactive protein and thrombocytopenia were not significant. I was aware that I was due to rotate through this unit and did not question that no qualified clinician had examined me. These doctors were my seniors, and I did not want a reputation as a paranoid hypochondriac before my first ward round there. I was discharged the next morning.

The fever got worse. I had not eaten in days, continued to rigor, and was beginning to hallucinate. I was due to fly to India for my brother's wedding when I saw my general practitioner again. She commented that I looked "awful," which I found strangely reassuring-I was not wasting another senior clinician's time.
She expertly discovered a new murmur and the splinter haemorrhages that I had missed.

The diagnosis of endocarditis was devastating and terrifying, but an excellent cardiology team ensured I was on my feet and back to work. Unfortunately I had not escaped complications; severe mitral regurgitation meant I was to face open heart surgery the next spring.

The six months between diagnosis and surgery rolled by, and I convinced myself that I was neither anxious nor unwell. At work I wanted no special treatment and undertook all my responsibilities as a junior doctor. I rotated through the medical assessment unit and even worked under the consultant who had dismissed me so quickly. He seemed to have no memory of me or my admission, and I did not ever mention it.

As surgery approached, I became very particular about planning every small detail I could-such as specific music for the hospital and which $\mathrm{T}$ shirt I would wear. I even reconciled with an old girlfriend when I discovered she would be the foundation year 1 doctor covering my postoperative ward. In retrospect, I realise that this was my way of hiding from the fear of it all. While I regarded the surgery itself as a matter of routine, what worried me was the outcome. The decision about whether to repair or replace the valve was to be made intraoperatively, the latter ensuring a limited valve life and ongoing warfarin treatment. I was wheeled into theatre with my future uncertain. My memory of events in the intensive care unit after surgery, intubated and sedated, feels unshakably real. However, these memories proved to be inaccurate in both sequence and content when I recounted them to those present.

All I can recollect from those 18 hours are events that had an association with the people and world I knew. A friendly visitor or piece of medical jargon would punctuate the fog of my stay with momentary clarity. My thought process at the time was 
totally devoid of both insight and emotion. Even being told that the valve repair had been successful, and the replacement I feared had been avoided, was processed purely as a fact. There was no elation, no relief. Being sedated was like living a synchronous yet separate life from reality.

My first visitor was Robin, a good friend from medical school. I clearly remember him leaning over my bed with the same sympathetic smile and manner he has always used with patients. I later learnt this was fiction; he was actually teasing me for squeezing his hand with uncharacteristic affection. I could only salivate in response. I can't explain my clear visualisation, as he assures me I did not open my eyes. I wonder if all sedated patients are like me, apparently using past experiences to make sense of current events.

Unconscious and intubated, I was relying on my instincts. My training certainly influenced how I behaved, although this was not necessarily appreciated by the nursing staff. We are drilled in the benefits of patient controlled analgesia as medical students, and this was reiterated preoperatively by my anaesthetist. My brain told me I had had an operation and therefore I must push the button. So I did-excessively. I was pain-free throughout, yet I could overhear the staff discussing increasing my analgesia in response to my unrelenting use of the analgesia button.

Experience had also taught me that a poor arterial trace can be the result of suboptimal positioning of an arterial line. When I overheard a visiting colleague discuss my low blood pressure reading my right arm became completely disinhibited, and I started waving it around like an elated dog's tail, perhaps in a subconscious attempt to improve the trace. Thereafter, only physical restraint from my nurse came close to achieving optimal positioning.

Before surgery I was concerned that delirium would be a feature of my stay, and I feared being sectioned. It seems that a visitor could act as a trigger to my vulnerable mind, precipitating florid auditory and visual hallucinations. A colleague jokingly commented on the height of my "ST segments." Consequently, a fictional registrar requested a fictional troponin level. A fictional group of nurses then refused to carry out the request, arguing their case by sketching a fictional graph of cardiac enzymes on the wall in permanent black marker. When I was lucid the following day, this sketch was notably absent.

My first conscious thought process was my desire to be extubated, which seemed to go on for hours. I could hear the nurses saying that I was not yet awake enough to be extubated, but I was thinking, "Yes I am, I just can't tell you." Despite the sensation of choking, I was not distressed; rather I was frustrated as I struggled to get my point across. I found that biting the tube led to more sedation, so I eventually gave up and then somehow got my wish. I had completed my adventure through fiction and delirium to conscious thought and extubation.

My journey concluded five weeks later, back in the intensive care unit, but this time as a foundation year 2 doctor. I was concerned that my return to the same environment might trigger suppressed emotions. Thankfully this fear was unjustified. My only apprehension was of being singled out from my new colleagues, so I hid my sternotomy scar with a T shirt under my scrubs.

Could things have been different had I insisted on a further examination on my initial presentation? Could I have avoided surgery and a sternotomy scar? These questions will remain unanswered, but I have been fortunate that my journey has had a positive ending. Having been a patient in the intensive care unit, I then discovered a love for intensive care as a doctor and, one year later, began training in anaesthesia and critical care. My experience has given me a greater insight into life as a patient than I ever would have wanted, but it has equipped me with a great deal of empathy and understanding for patients as I now play my role in their similar journeys.

Competing interests: All authors declare no support from any organisation for the submitted work; no financial relationships with any organisations that might have an interest in the submitted work in the previous three years; no other relationships or activities that could appear to have influenced the submitted work.

Provenance and peer review: Not commissioned; not externally peer reviewed.

Accepted: 08 September 2011

Cite this as: BMJ 2012;344:e2971

(c) BMJ Publishing Group Ltd 2012 


\section{A doctor's perspective}

This 27 year old man attended the emergency department with symptoms of a sore throat, vomiting, and rigors. His temperature was $38.5^{\circ} \mathrm{C}$, but all other vital parameters were normal. No abnormal findings were noted on physical examination. Blood tests were in the normal range except for an elevated $\mathrm{C}$ reactive protein at $218 \mathrm{mg} / \mathrm{L}$ and a depressed platelet count at $64 \times 10^{\circ} / \mathrm{L}$. He was admitted to the medical assessment unit with the diagnosis of viral gastroenteritis and was assessed by the general medical consultant. A further physical examination by a doctor was not undertaken, and he was discharged after intravenous fluid therapy.

The patient was readmitted to hospital four days later, after his general practitioner, having noted splinter haemorrhages and a pansystolic murmur radiating to the axilla, raised the possibility of infective endocarditis. His C reactive protein remained elevated at $194 \mathrm{mg} / \mathrm{L}$. Three sets of blood cultures were taken.

A transthoracic echocardiogram suggested a vegetation attached to the anterior mitral valve (figure $\downarrow$ ). A diagnosis of infective endocarditis was made, and he was started on a course of benzylpenicillin and gentamicin. A second transoesophageal echocardiogram revealed the anterior valve leaflet was normal, but the posterior mitral valve leaflet was partially destroyed, had a perforation, and was prolapsing with a resultant jet of severe mitral regurgitation (figure $\downarrow$ ). There were two vegetations seen oscillating on the posterior valve leaflet. This shows the limited ability of transthoracic scans in this scenario.

Blood cultures taken during the second admission grew a Gram negative bacillus. This was identified as Haemophilus parainfluenzae type $\mathrm{b}$, and the antibiotic regimen was rationalised to ceftriaxone. There was an excellent clinical response, with the $\mathrm{C}$ reactive protein falling to below $10 \mathrm{mg} / \mathrm{L}$.

The patient was discharged home. Although his infective parameters remained in the normal range, he became breathless on exertion. Repeat transoesophageal echocardiography revealed a flail segment on the posterior mitral valve leaflet with a ruptured chord and a healed vegetation. The severe mitral regurgitation was still evident, and the case was discussed with the cardiothoracic surgery team, who offered a repair operation.

The repair was carried out successfully with subsequent echocardiography revealing a fully competent mitral valve. In the weeks after surgery the patient improved clinically with an enhanced exercise tolerance. He has remained under clinical follow-up and has been in excellent health.

The patient would almost certainly have had signs of endocarditis on his first hospital admission, but he was examined only once in a busy emergency department and the splinter haemorrhages and murmur were not appreciated. The opportunity to take blood cultures in a feverish and ill young man with a high $\mathrm{C}$ reactive protein was not taken. I also note he was working within a tertiary referral hospital for three days with unrecognised Gram negative sepsis.

The patient was clearly worried about the prospect of a mitral valve replacement as opposed to repair. The discussion between the cardiology and cardiothoracic team in this regard was very much routine. It is interesting to be reminded how much these decisions affect a patient's anxiety and long term wellbeing.

Shirjel Alam

\section{Resources for patients}

Patient.co.uk provides a comprehensive information service for patients with a wide range of conditions, including infective endocarditis-www.patient.co.uk/health/Endocarditis-Infective.htm

\section{Figure}

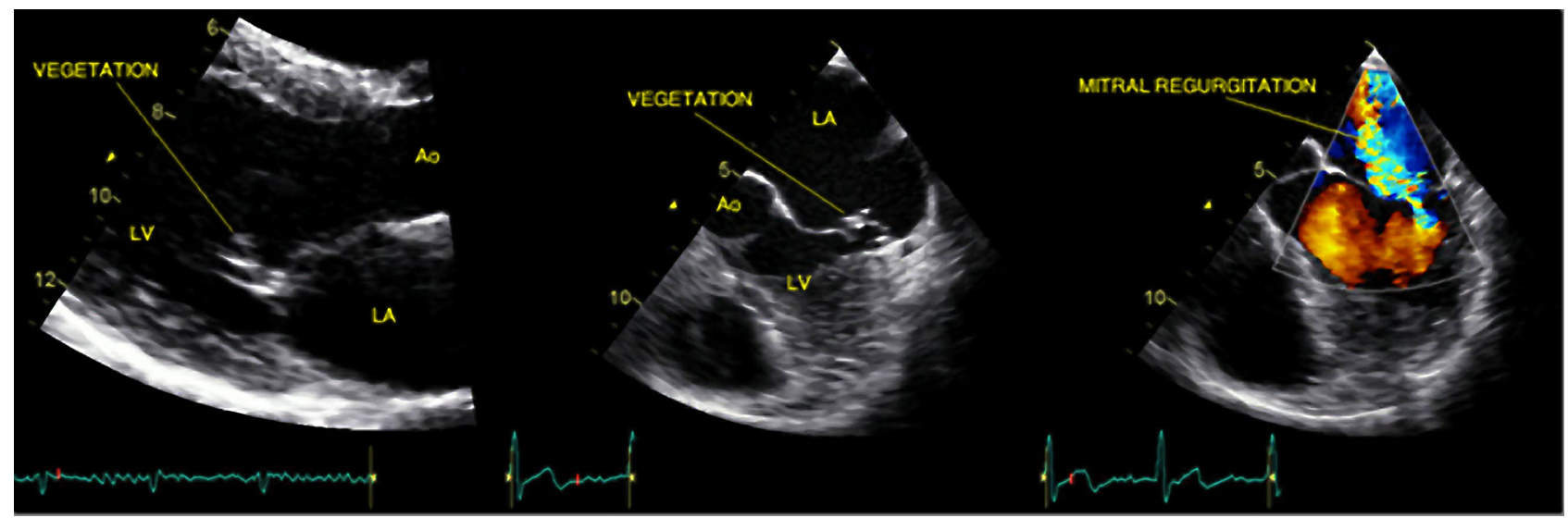

Transthoracic echocardiograms of patient. Initial echocardiogram (left) seemed to show vegetation on the anterior mitral leaflet. A second echocardiogram showed vegetation on the posterior mitral valve leaflet (middle) and jet of mitral regurgitation (right). $L V=$ left ventricle, $L A=l e f t$ atrium, Ao=aortic outflow 